\title{
Características produtivas de cultivares de batata-doce em duas épocas de colheita, em Porteirinha - MG.
}

\author{
Geraldo M. de Resende
}

Embrapa Semi-Árido, C. Postal 23, 56.300-000 - Petrolina-PE e-mail: gmilanez@cpatsa.embrapa.br

\begin{abstract}
RESUMO
Com o objetivo de avaliar a produtividade e a qualidade de raízes de cultivares de batata-doce e identificar a melhor época de colheita, conduziu-se um experimento no Campo Experimental do Gorutuba, em Porteirinha-MG, de novembro de 1990 a junho de 1991. Foram estudadas cinco cultivares de batata-doce (Brazlândia Branca, Brazlândia Rosada, Brazlândia Roxa, Princesa e Paulistinha) e duas épocas de colheita ( 150 e 200 dias após plantio), arranjadas em esquema fatorial $5 \times 2$, no delineamento experimental de blocos casualizados, com cinco repetições. Verificou-se, para a colheita aos 150 dias após o plantio, que a cultivar Brazlândia Branca foi $62,7 \%$ mais produtiva $(22,84 \mathrm{t} / \mathrm{ha})$ que a cultivar Brazlândia Roxa (14,33 t/ha), a menos produtiva. Aos 200 dias de ciclo, a cultivar Paulistinha foi a mais produtiva $(54,50 \mathrm{t} / \mathrm{ha})$, sendo a menor produtividade apresentada pela cultivar Brazlândia Rosada (55,0\% menos produtiva que a cultivar Paulistinha). A cultivar Brazlândia Roxa apresentou maior produção de refugos, de 7,76 e 12,38 t/ha, respectivamente, para a colheita aos 150 e aos 200 dias após o plantio. Para peso médio de raiz, houve uma variação de 220,12 a $504,95 \mathrm{~g}$, sendo que todas as cultivares apresentaram maior porcentagem de raízes graúdas (400-800 g/raiz), quando colhidas mais tardiamente. Recomenda-se a colheita das cultivares Paulistinha, Brazlândia Rosada e Brazlândia Branca aos 150 dias após o plantio, pelo tamanho menor de raízes preferidas pelo consumidor. Já para a cultivar Princesa, em função da sua menor produção de raízes tipo 2 (400 a $800 \mathrm{~g} / \mathrm{raiz}$ ) comparativamente às cultivares anteriores, sua colheita pode ser feita de 150 até 200 dias após o plantio. A cultivar Brazlândia Roxa apresentou melhor desempenho quando colhida aos 200 dias após o plantio.
\end{abstract}

Palavras-chave: Ipomoea batatas, raiz tuberosa, produtividade.

\begin{abstract}
Yield characteristics of sweet potato cultivars under different harvest periods in Porteirinha, Minas Gerais State, Brazil.

With the objective of evaluating sweet potato cultivars under different harvest periods, one experiment was carried at the Gorutuba Experimental Field, Porteirinha-MG, Brazil, from November 1990 to June 1991. The experimental design was a randomized complete block in a $5 \times 2$ factorial arrangement with four replications. The first factor consisted of five cultivars (Brazlândia Branca, Brazlândia Rosada, Brazlândia Roxa, Princesa and Paulistinha) and the second one of two harvest times (150 and 200 days after planting). For the harvest at 150 days after planting, the cv. Brazlândia Branca yielded $62.7 \%$ more (22.84 ton/ha), than the cv. Brazlândia Roxa (14.44 ton/ha). For the harvest at 200 days after planting, the cv. Paulistinha had the highest yield (54.50 ton/ha), and cv. Brazlândia Rosada had the lowest yield, 55.0\% less productive than the cv. Paulistinha. The cv. Brazlândia Roxa showed the highest non-commercial yield of 7.76 and 12.38 ton/ha, respectively, for the harvests at 150 and 200 days after planting. The mean root weight, renged from 220.12 to $504,95 \mathrm{~g}$, and all the cultivars showed higher percentage of big roots (400-800 g/root) when harvested later. cv. Paulistinha, Brazlândia Rosada and Brazlândia Branca can be harvested 150 days after planting. cv. Princesa can be harvested at 150 days of planting extended up to 200 days due to its lowest yield of big roots. cv. Brazlândia Roxa, harvested at 200 days after planting, had the best performance.
\end{abstract}

Keywords: Ipomoea batatas, root tuber, yield.

\section{( Aceito para publicação em 17 de janeiro de 2.000)}

$\mathrm{P}$ anta de fácil cultivo, rústica e de ampla adaptação, a batata-doce é amplamente difundida, estando dentre as doze culturas fundamentais do mundo (Barreira, 1986), de grande importância social e econômica vislumbrando-se sua participação efetiva no suprimento de alimentos. Além disso, constitui-se numa excelente alternativa para a alimentação animal e para a agroindústria (Thomazelli et al., 1997), apresentando produtividade média mundial de 14,93 t/ha (FAO,1998) e nacional de 11,31 t/ha (ANUÁRIO, 1996), sendo que uma boa produtividade se situa entre 9 e 14 t/ha de acordo com Yamaguchi (1983).
O ciclo da cultura varia entre 90 e 240 dias (Vernier \& Varin, 1994), 150 a 210 dias (Khatounian, 1994), 150 a 240 dias (Smith \& Mantengo, 1995), dependendo da cultivar e das condições ambientes. A época de colheita varia de acordo com a destinação do produto. Para mesa, a batata-doce deve ser colhida tão logo atinja o tamanho ideal de comercialização, o que geralmente ocorre dos 100 aos 110 dias para as cultivares precoces até aos 180 dias para as tardias. Para a indústria, pode ser colhida mais tarde (Miranda et al., 1984).

Avaliando doze clones de batatadoce, no espaçamento de $0,80 \times 0,30 \mathrm{~m}$, em Anápolis-GO, sob uso de irrigação por aspersão com colheita aos 152 dias, Peixoto et al. (1989) observaram produtividades variando de 16,7 a 27,0 t/ha, sendo a cultivar Brazlândia Branca a mais produtiva (26,7 t/ha), seguida pela Princesa (26,6 t/ha), Brazlândia Rosada (25,8 t/ha), Coquinho (18,1 t/ha) e Brazlândia Roxa (17,7 t/ha). A produção de refugos oscilou entre 1,6 e 4,5 t/ha e a maior foi a da 'Brazlândia Roxa' (4,5 t/ha). O peso médio de raízes variou de 183,3 g (Brazlândia Roxa) a 232,1 g (Brazlândia Rosada). Utilizando o espaçamento de $0,80 \times 0,40 \mathrm{~m}$, Mendonça \& Peixoto (1991), no mesmo local, observaram 
Tabela 1. Produtividade comercializável e de refugo (t/ha) de cultivares de batata-doce, em duas épocas de colheita. Porteirinha (MG), EPAMIG, 1990/91.

\begin{tabular}{llllllll}
\hline \multirow{2}{*}{ Cultivares } & \multicolumn{3}{c}{ Comercializável } & \multicolumn{4}{c}{ Refugo } \\
\cline { 2 - 8 } & $\mathbf{1 5 0}$ dias & $\mathbf{2 0 0}$ dias & $\mathbf{1 5 0}$ dias & $\mathbf{2 0 0}$ dias \\
\hline Brazlândia Branca & $22,84 \mathrm{a}^{1}$ & 39,35 & $\mathrm{~b}$ & 4,89 & $\mathrm{~b}$ & $11,00 \mathrm{a}$ \\
Paulistinha & $22,11 \mathrm{ab}$ & $54,50 \mathrm{a}$ & 3,37 & $\mathrm{~b}$ & 6,01 & $\mathrm{~b}$ \\
Princesa & $19,79 \mathrm{ab}$ & 42,82 & $\mathrm{~b}$ & 2,90 & $\mathrm{~b}$ & 3,08 & $\mathrm{c}$ \\
Brazlândia Rosada & $16,93 \mathrm{ab}$ & 29,99 & $\mathrm{C}$ & 4,22 & $\mathrm{~b}$ & 3,26 & $\mathrm{c}$ \\
Brazlândia Roxa & 14,33 & $\mathrm{~b}$ & 35,66 & bc & 7,76 & $\mathrm{a}$ & $12,38 \mathrm{a}$ \\
\hline C.V. (\%) & \multicolumn{3}{c}{14,42} & \multicolumn{5}{c}{20,77} \\
\hline
\end{tabular}

${ }^{1}$ Médias seguidas pela mesma letra na colunas, não diferem entre si, pelo teste de Tukey, ao nível de $5 \%$.

maiores produtividades para as cultivares Brazlândia Branca $(20,21 \mathrm{t} / \mathrm{ha}) \mathrm{e}$ Brazlândia Roxa (19,54 t/ha) e peso médio de raiz de 220,08 e $197,54 \mathrm{~g}$, respectivamente, com ciclo de 152 dias e plantio no período chuvoso (dezembro).

Durante o desenvolvimento da planta, são necessários $25 \mathrm{~mm}$ de água por semana e um total de 450-600 $\mathrm{mm}$ no ciclo (Yamaguchi, 1983). Peterson, citado por King (1985), relata que $25 \mathrm{~mm}$ de água por semana resultaram em maiores produtividades que quando se aplicou uma lâmina de água de $12 \mathrm{~mm}$, o que equivale a $500 \mathrm{~mm}$ por um período de cinco meses de ciclo.

Aplicando-se uma lâmina de $10 \mathrm{~mm}$ em irrigações a cada dois dias, com plantio em novembro e colheita em maio (seis meses), Cecílio Filho et al. (1998) verificaram maior produtividade para a cultivar Brazlândia Branca (20,50 t/ha), seguida da 'Brazlândia Rosada' (9,35 t/ ha) e da 'Coquinho' (6,02 t/ha) em Lavras-MG. Em condições irrigadas no norte de Minas Gerais, colhendo aos 150 dias após o plantio, Resende (1999) verificou maior produtividade para as cultivares Brazlândia Branca (22, 3 t/ha), Paulistinha (21,3 t/ha) e Princesa (19,0 t/ha), que não tiveram diferenças significativas entre si.

Este trabalho teve como objetivo avaliar o potencial produtivo de cultivares de batata-doce em duas épocas de colheita no período chuvoso, com irrigação suplementar, nas condições da região Norte de Minas Gerais.

\section{MATERIAL E MÉTODOS}

O experimento foi conduzido no período de novembro de 1990 a junho de 1991 no Campo Experimental do Gorutuba, Porteirinha-MG, situada a $15^{\circ} 47^{\prime}$ de Latitude Sul e $43^{\circ} 18^{\prime}$ de Longitude Oeste, com altitude de 516 m. O clima, segundo a classificação de Köppen é do tipo AW, com verão chuvoso (outubro a março) e inverno seco, e o solo tipo aluvião, textura arenosa.

Foram estudadas cinco cultivares de batata-doce (Brazlândia Branca, Brazlândia Rosada, Brazlândia Roxa, Princesa e Paulistinha) e duas épocas de colheita (150 e 200 dias após plantio), arranjadas em esquema fatorial $5 \times 2$, no delineamento experimental de blocos casualizados, com cinco repetições. As parcelas constituíram-se de quatro fileiras de 4,5 m de comprimento, espaçadas de $0,80 \mathrm{~m}$ entre elas e $0,30 \mathrm{~m}$ entre plantas, sendo usadas como área útil as duas fileiras centrais. A adubação constou de $330 \mathrm{~kg} / \mathrm{ha}$ de superfosfato simples e $50 \mathrm{~kg} / \mathrm{ha}$ de cloreto de potássio, incorporados no sulco de plantio.

No plantio (29/11/90), foram utilizadas mudas com oito entrenós, ficando enterrados três a quatro transversalmente na leira, a uma profundidade de $0,10-0,15 \mathrm{~m}$. A cultura foi mantida no limpo, através de capinas manuais, não sendo realizados quaisquer tratos fitossanitários.

Registraram-se as seguintes precipitações pluviométricas $(\mathrm{mm})$ durante a realização do experimento: novembro 23,2; dezembro - 206,2; janeiro - 202,3; fevereiro - 54,20; março - 65,3; abril 23,2 ; maio - 12,6 e junho - $0,0 \mathrm{~mm}$, perfazendo um total de $694,4 \mathrm{~mm}$ até 150 dias após o plantio (dap) e 774,5 mm até os 200 dap. Foram realizadas três irrigações suplementares no meses de- zembro, fevereiro e março até 150 dap, e mais outras duas (abril e maio) até 200 dias, com lâminas em torno de $40 \mathrm{~mm}$.

As colheitas foram realizadas aos 150 e aos 200 dias após o plantio, sendo avaliadas as seguintes características: produtividade comercializável (raízes com peso entre 100 e $800 \mathrm{~g}$ ), refugo (raízes abaixo de $100 \mathrm{~g}$, rachadas, deformadas, esverdeadas, brocadas e com veias), peso médio de raiz comercializável e classificação de raízes comercializáveis em porcentagem (Tipo 1 - raízes entre 100 e 400 g e Tipo 2 - raízes entre 400 e 800 g). Os dados foram submetidos à análise de variância, aplicando-se o teste de Tukey até o nível de $5 \%$. Os dados de porcentagem foram transformados em arco-seno $\sqrt{(\mathrm{P} / 100)}$

\section{RESULTADOS E DISCUSSÃO}

Os resultados evidenciaram efeitos significativos da interação cultivares $\mathrm{x}$ épocas de colheitas para todas as características avaliadas.

A cultivar Branca foi $62,7 \%$ mais produtiva do que a 'Brazlândia Roxa', a menos produtiva, aos 150 dias após plantio (Tabela 1). Para a colheita aos 200 dias a cultivar Paulistinha foi a mais produtiva $(54,50 \mathrm{t} / \mathrm{ha})$, sendo o pior desempenho apresentado pela cultivar Brazlândia Rosada que foi $55,0 \%$ menos produtiva que a 'Paulistinha'. As produtividades obtidas estão acima da média mundial de 14,93 t/ha (FAO, 1998) e da nacional de $11,31 \mathrm{t} / \mathrm{ha}$ (ANUÁRIO, 1996). Peixoto et al. (1989), em Goiás, colhendo aos 152 dias após o plantio, também observaram maiores produtividades para as cultivares Brazlândia Branca (26,7 t/ha) e Princesa (26,6 t/ha) e menor para a cultivar Brazlândia Roxa (17,7 t/ha). Mendonça \& Peixoto (1991) também constataram ser a cultivar Brazlândia Branca mais produtiva que a 'Brazlândia Roxa' e Kurihara et al. (1993) relatam para as cultivares Brazlândia Branca, Brazlândia Rosada, Brazlândia Roxa e Princesa produtividades variando de 15 a $18 \mathrm{t} / \mathrm{ha}$, necessitando de irrigações na época seca. Por outro lado, as produtividades obtidas foram inferiores às 25 $30 \mathrm{t} / \mathrm{ha}$ informadas por Miranda et al. (1989) para as cultivares Brazlândia Branca, Brazlândia Rosada, Brazlândia 
Tabela 2. Peso médio e classificação de raízes de cultivares de batata-doce, em duas épocas de colheita. Porteirinha (MG), EPAMIG, $1990 / 91$.

\begin{tabular}{|c|c|c|c|c|c|c|}
\hline \multirow{3}{*}{ Cultivares } & \multirow{2}{*}{\multicolumn{2}{|c|}{ Peso médio de raiz(g) }} & \multicolumn{4}{|c|}{ Classificação de raízes (\%) } \\
\hline & & & \multicolumn{2}{|c|}{ Tipo1 } & \multicolumn{2}{|c|}{ Tipo 2} \\
\hline & 150 dias & 200 dias & 150 dias & 200 dias & 150 dias & 200 dias \\
\hline Brazlândia Rosada & $319,46 a^{1}$ & $387,17 \quad b$ & 81,71 bc & $44,58 \quad c$ & $18,29 \quad b$ & $55,43 a$ \\
\hline Brazlândia Branca & $278,43 a b$ & $397,55 \quad b$ & $78,88 \quad c$ & $53,17 \mathrm{~b}$ & $21,12 a b$ & $46,83 \mathrm{~b}$ \\
\hline Paulistinha & $261,04 a b$ & $504,94 a$ & $75,21 \quad c$ & $41,37 \mathrm{C}$ & $24,79 a$ & 58,63 a \\
\hline Princesa & $256,35 \mathrm{~b}$ & $381,00 \quad b$ & $86,41 \mathrm{~b}$ & $58,14 \mathrm{~b}$ & 13,59 & 41,86 b \\
\hline Brazlândia Roxa & $220,12 b$ & $276,97 \quad c$ & $92,19 \mathrm{a}$ & $72,42 \mathrm{a}$ & 7,81 & 27,58 \\
\hline C.V. (\%) & & & & & & \\
\hline
\end{tabular}

${ }^{1}$ Médias seguidas pela mesma letra nas colunas, não diferem entre si, pelo teste de Tukey, ao nível de 5\%.

Tipo 1 = raízes entre 100 e $400 \mathrm{~g}$

Tipo 2 = raízes entre 400 e $800 \mathrm{~g}$

Roxa, em ciclo de 120-150 dias e superiores às produtividades relatadas por Cecílio Filho et al. (1998), para as cultivares Brazlândia Branca (20,50 t/ha) e Brazlândia Rosada (9,35 t/ha), colhendo aos 180 dias.

Comparando-se as produtividades nos dois ciclos estudados (Tabela 1), verificaram-se incrementos, dos 150 aos 200 dias de ciclo, de 72,27; 146,49; 116,$37 ; 77,14$ e $148,85 \%$ para as cultivares Brazlândia Branca, Paulistinha, Princesa, Brazlândia Rosada e Brazlândia Roxa, respectivamente, em função do maior período de permanência da cultura no campo (ciclo). Estes incrementos, aliados à produção de refugos, peso médio de raiz e classificação de raízes, indicam o melhor ciclo para as diferentes cultivares em estudo. Resultados semelhantes com relação a refugos foram encontrados por Peixoto et al. (1989), que verificaram uma maior produção para a cultivar Brazlândia Roxa. Salienta-se, no entanto, que a produção de refugos foi proporcionalmente maior devido à produção de raízes com peso inferior a $100 \mathrm{~g}$ e raízes deformadas, não sendo constatado ataque de pragas de solo por ocasião da colheita, ao contrário do que diversos autores relatam como um dos principais fatores de produção de raízes nãocomercializáveis de batata-doce (Peixoto \& Miranda, 1984; King, 1985; EMPASC/ACARESC, 1990).

No que se refere ao peso médio de raiz, verificou-se uma variação de 220,12 a 504,94 g/raiz (Tabela 2), sobressaindo-se, aos 150 e 200 dias após o plantio, as cultivares Brazlândia Ro- sada e Paulistinha que mostraram-se 68,9 e $55,4 \%$ superiores à cultivar Brazlândia Roxa que apresentou os menores pesos médios de raiz, nas duas épocas de colheita. Os pesos médios das cultivares Brazlândia Branca e Brazlândia Roxa (Tabela 2), foram superiores aos obtidos por Mendonça \& Peixoto (1991) colhendo aos 150 dias após o plantio (222,08 e 197,54 g/raiz, respectivamente). Resultados similares foram constatados por Peixoto et al. (1989), que observaram maior peso médio de raiz para a cultivar Brazlândia Rosada, colhendo aos 176 dias após o plantio, e por Miranda (1989) que relata uma maior produção de batatas graúdas, de elevado peso médio quando aquela cultivar é colhida após 120150 dias de ciclo.

Aos 150 dias o após plantio, para a classificação de raízes comerciais em porcentagem (Tabela 2), observa-se que todas as cultivares a exceção da cultivar Brazlândia Roxa, apresentaram menos de $92,19 \%$ de raízes entre 100 e $400 \mathrm{~g}$ e mais de $13,0 \%$ de raízes entre 400 e $800 \mathrm{~g}$. Para a colheita aos 200 dias após o plantio, a cultivar Brazlândia Roxa sobressaiu-se, com maior porcentagem de raízes entre 100 a $400 \mathrm{~g}$ $(72,42 \%)$, comparativamente às demais cultivares que apresentaram maiores porcentagens de raízes graúdas (400 a $880 \mathrm{~g} / \mathrm{raíz}$ ). Segundo Silveira et al. (1997), o tamanho ideal de batatas para o comércio está entre 200 e $500 \mathrm{~g}$ e Silva et al. (1991) informam que para as condições do Rio de Janeiro e São Paulo, está entre 150 e 400g; para mercados menos exigentes, oscila entre 151 a $800 \mathrm{~g}$ para a classificação de especial a extra A. Neste contexto, as cultivares avaliadas atendem plenamente às exigências do mercado consumidor brasileiro.

Apesar de todas as cultivares apresentarem melhores produtividades aos 200 dias após o plantio, recomenda-se a colheita das cultivares Paulistinha, Brazlândia Rosada e Brazlândia Branca aos 150 dias após o plantio; para a cultivar Princesa, em função da sua menor produção de raízes tipo 2 (400 a $800 \mathrm{~g} / \mathrm{raíz}$ ), comparativamente às cultivares anteriores, pode-se inferir que sua colheita seja realizada aos 150 dias, podendo ser estendida até 200 dias após o plantio. A cultivar Brazlândia Roxa pelo seu desempenho quanto às diferentes características avaliadas, deverá ser colhida aos 200 dias após o plantio, corroborando as afirmações de Miranda et al. (1989) e Miranda (1989), de ser esta cultivar mais tardia. Esta recomendação baseia-se no fato da preferência dos consumidores recaírem sobre batatas de menor tamanho, assim como pela menor exposição da cultura ao ataque de pragas de solo, uma vez que quanto mais tempo a batata-doce permanecer no solo maior a possibilidade de ocorrerem pragas, sobretudo broca da raiz, cujas larvas danificam as raízes internamente e externamente, prejudicando o seu aspecto físico, o odor e o sabor, ficando imprestáveis para o consumo; conforme relatam Peixoto \& Miranda (1984) e Miranda et al. (1989), que recomendam a colheita precoce como uma das medidas gerais de controle de insetos de solo. 


\section{LITERATURA CITADA}

ANUÁRIO ESTATÍSTICO DO BRASIL. Rio de Janeiro: IBGE, v. 56, 1996. p. 3-42.

BARREIRA, P. Batata-doce: uma das doze mais importantes culturas do mundo. São Paulo: Editora Ícone, 1986. 92 p.

CECÍLIO FILHO, A.B.; REIS, M. dos S.; SOUZA, R.J. de; PASQUAL, M. Degenerescência em cultivares de batata-doce. Horticultura Brasileira, Brasília, v. 16, n. 1, p. 82-84, 1998.

EMPASC/ACARESC. Normas técnicas para a cultura da batata-doce; Santa Catarina. Florianóplis: EMPASC/ ACARESC, 1991. 21 p. (EMPASC/ACARESC. Sistemas de produção, 15).

FAO QUATERLY BULLETIN OF STATISTICS. Rome: FAO, v. 11, n. 112, p. 40-41, 1998.

KHATOUNIAN, C.A. Produção de alimentos para consumo doméstico no Paraná: caracterização e culturas alternativas. Londrina: IAPAR, 1994. 193 p. (IAPAR. Circular, 81).

KING, G.A. The effect of time of planting on yield of six varieties of sweet potato (Ipomoea batatas (L) Lam.) in southern costal lowlands of Papua New Guinea. Tropical Agriculture, v. 62, n. 3, p. 225-228, 1985.

KURIHARA, C.; GOMES, G.C.; MATOS, F.A.C.; QUINDERÉ JUNIOR, R.A.G. Recomendações técnicas para a produção e comercialização de hortaliças para o periodo de entressafra no Distrito Federal. Brasília: EMBRAPA-SPI/EMATER-DF, 1993. 43 p.
MENDONÇA, A.T.C.; PEIXOTO, N. Efeitos do espaçamento e de níveis de adubação em cultivares de batata-doce. Horticultura Brasileira, Brasília, v. 9, n. 2, p. 80-82, 1991.

MIRANDA, J.E.C. de. Brazlândia Roxa, Brazlândia Branca, Brazlândia Rosada e Coquinho: novas cultivares de batata-doce. Horticultura Brasileira, Brasília, v. 7, n. 1, p. 32-33, 1989.

MIRANDA, J.E.C. de; FRANÇA, F.H.; CARRIJO, O.A.; AGUILAR, J.A.E. Cultivo de batata-doce (pomoea batatas (L) Lam). Brasília: EMBRAPA-CNPH, 1984. 8 p. (Embrapa Hortaliças. Instruções Técnicas, 7).

MIRANDA, J.E.C. de; FRANÇA, F.H.; CARRIJO, O.A.; SOUZA A.F.; PEREIRA, W.; LOPES, C.A. Batata-doce (Ipomoea batatas (L) Lam). Brasília: EMBRAPA/CNPH, 1989. 20 p. (Embrapa Hortaliças. Circular Técnica, 3).

PEIXOTO, N.; MIRANDA, J.E.C. de. O cultivo da batata - doce em Goiás. Goiânia: EMGOPA-DDI, 1984. 24 p. (EMGOPA. Circular Técnica, 7).

PEIXOTO, N., MIRANDA, J.E.C. de; FILGUEIRA, F.A.R.; CÂMARA, F.L.A. Avaliação de clones de batata-doce em Goiás. Goiânia: EMGOPA-DDT, 1989. 12 p. (EMGOPA, Boletim de Pesquisa, 16).

RESENDE, G.M. de. Características produtivas de cultivares de batata-doce sob condições irrigadas e de sequeiro na região norte de Minas Gerais. Horticultura Brasileira, Brasília, v. 17 , n. 2 , p. $151-154,1999$.
SILVA, L.O. ; CALBO, A.G.; HENZ, G.P. Classificação e beneficiamento de hortaliças. Informe Agropecuário, Belo Horizonte, v. 15, n. 169 , p. 48-53, 1991.

SILVEIRA, M.A. da; AZEVEDO, S.M .de; MALUF, W.R.; CAMPOS, V.P.; MOMENTÉ V.G. Canuanã e Palmas: novas cultivares de batata-doce resistentes aos nematóides-degalhas. Horticultura Brasileira, Brasília, v. 15 n. 2, p. 122-123, 1997.

SMIT, W.E. J.M.; MANTENGO, L.O. Farmer's cultural practices and their effects on pest control in sweet potato in south Nyanza, Kenia. International Journal of Pest Management, $\mathrm{v}$. 41, n. 1, p. 2-7, 1995.

THOMAZELLI, L.F.; GANDIM, C.L.; ALMEIDA, E.X.; BOFF, P. Novas tecnologias para o cultivo da batata-doce em SC. Agropecuária Catarinense, Florianópolis, v. 10, n. 1, p. 12-14, 1997.

VERNIER, P.; VARIN, D. La culture de la patate douce. Agriculture et devéloppement, n. 3, p. 54-63, 1994.

YAMAGUCHI, M. World vegetables: principles, production and nutritive values. Westport: AVI, 1983. $415 \mathrm{p}$ 